\title{
Fast production of microwave component prototypes by additive manufacturing and
} copper coating

Korsholm, S.B.; Leipold, F.; Madsen, R.B.; Gutierrez , H.; Jensen, T.; Jessen, M.; Larsen, A.W.;

Rasmussen, J.; Salewski, M.

Published in:

Review of Scientific Instruments

Link to article, DOI:

$10.1063 / 5.0043816$

Publication date:

2021

Document Version

Peer reviewed version

Link back to DTU Orbit

Citation (APA):

Korsholm, S. B., Leipold, F., Madsen, R. B., Gutierrez , H., Jensen, T., Jessen, M., Larsen, A. W., Rasmussen, J., \& Salewski, M. (2021). Fast production of microwave component prototypes by additive manufacturing and copper coating. Review of Scientific Instruments, 92, [033509]. https://doi.org/10.1063/5.0043816

\section{General rights}

Copyright and moral rights for the publications made accessible in the public portal are retained by the authors and/or other copyright owners and it is a condition of accessing publications that users recognise and abide by the legal requirements associated with these rights.

- Users may download and print one copy of any publication from the public portal for the purpose of private study or research.

- You may not further distribute the material or use it for any profit-making activity or commercial gain

- You may freely distribute the URL identifying the publication in the public portal 


\title{
Fast Production of Microwave Component Prototypes by Additive Manufacturing and Copper Coating
}

\author{
S.B. Korsholm, ${ }^{1, a)}$ F. Leipold, ${ }^{1,{ }^{*}}$ R.B. Madsen ${ }^{2}$, H. Gutierrez,${ }^{1}$ T. Jensen, ${ }^{1}$ M. Jessen,${ }^{1}$ A.W. Larsen, ${ }^{1}$ \\ J. Rasmussen, ${ }^{1}$ and M. Salewski ${ }^{1}$
}

${ }^{I}$ Technical University of Denmark, Department of Physics, 2800 Kgs. Lyngby, Denmark

${ }^{2}$ Polyteknik AS, 9750 Østervrå, Denmark

\begin{abstract}
(Presented XXXXX; received XXXXX; accepted XXXXX; published online XXXXX)
(Dates appearing here are provided by the Editorial Office)

We present a novel method for efficient production of prototypes of microwave components by fused depositing modelling (FDM), also known as 3D plastic printing, and vapor deposition coating of a 1 micron copper layer. We demonstrate that the properties of the components follow the predicted performance for low power microwave propagation. The production method offers new opportunities for cheap and efficient production of mock-ups and prototypes of advanced-geometry components for tests with low-power microwaves.
\end{abstract}

\section{INTRODUCTION}

\section{A. Context of the work}

The work presented in this paper relates to the development and design of the Collective Thomson Scattering (CTS) diagnostic system for ITER ${ }^{1-8}$. The CTS diagnostic is a primary diagnostic for the measurement of the confined fast ions in ITER - most importantly the fusion-born alpha particles. The optimal and chosen probing frequency for ITER CTS is $60 \mathrm{GHz}$ provided by a $1-1.3 \mathrm{MW}$ gyrotron. The frequency range of the received scattered CTS signal is $+/-5 \mathrm{GHz}$ relative to the probe. The diagnostic will perform simultaneous measurements in seven scattering volumes across the ITER plasma cross section with a spatial resolution ranging from $10 \mathrm{~cm}$ to $100 \mathrm{~cm}$ (Low Field Side to High Field Side) and a temporal resolution of $100 \mathrm{~ms}$. The alpha particle energy range $\mathrm{e}^{2}$ to which the CTS diagnostic is sensitive, is from 0.3 to 3.5 $\mathrm{MeV}$.

The primary task of the design team, led by the Technical University of Denmark (DTU) under the Fusion for Energy Framework Partnership Agreement F4E-FPA393 , is to develop the in-vessel front-end design located in equatorial port plug \#12. The in-vessel gyrotron transmission line consists of a number of quasi-optical mirrors, $\varnothing 88.9 \mathrm{~mm}$ circular corrugated (CC) waveguides (WG) and miter bends. Part of the scattered CTS signal is picked up by seven secondary receiver mirrors sharing a common plasma-facing mirror. The receiver mirrors direct the received signal towards seven receiver transmission lines with $\emptyset 31.75 \mathrm{~mm}$ CC WG.

\footnotetext{
a) Author to whom correspondence should be addressed

sbko@fysik.dtu.dk.

${ }^{*}$ Deceased, $17^{\text {th }}$ October 2018
}

In order to verify the efficiency and tolerances of the designed transmission line components, and also to verify the microwave component design and modeling codes, a series of prototype tests has been planned and executed. We have developed different prototype manufacturing and testing strategies depending on the nature and context of the components. In the case of corrugated and advanced components like horns and miter bends, we have developed the method presented in this paper: fused depositing modelling $(\mathrm{FDM}) / 3 \mathrm{D}$ plastic printing and vapor deposition coating of $\mathrm{a} \geq 1 \mu \mathrm{m}$ copper layer - in a collaboration between DTU and the Danish company Polyteknik AS.

While the presented prototypes are specific to the ITER CTS system, the presented production and test methods are applicable to many $\mathrm{GHz}$ frequency microwave transmission line component prototypes - and actually also non-vacuum operational low power components. Thus, we report this work to share our experiences with this time- and costefficient production of prototypes.

\section{B. Overview of the paper}

The paper is organized with a contextual description of the production of prototype components for microwave transmission lines in Section II, while Section III addresses how additive manufacturing or $3 \mathrm{D}$ printing can be used for production of corrugated component prototypes. The Polyteknik copper coating setup and process is described in Section IV, while the experimental verification of the performance of the copper-coated 3D plastic printed horn is presented in Section V. The perspectives of the method are discussed in the concluding Section VI. 


\section{PROTOTYPES OF MICROWAVE TRANSMISSION LINE COMPONENTS}

\section{A. Quasi-optical mirrors}

The CTS system we have been and are developing and utilizing $^{9-12}$ all operate at frequencies between $60 \mathrm{GHz}$ and $170 \mathrm{GHz}$. At these frequencies, the wavelengths allow for the use of ordinary aluminum foil as reflecting surface material. This, combined with high precision fused deposition modelling (FDM) - more popularly called 3D plastic printing - allows inexpensive and rapid production of prototypes of quasi-optical transmission line mirrors. After modeling the mirror surface and designing the mirror in the 3D CAD CATIA ${ }^{13}$ software, the CAD models are submitted to our FORTUS ${ }^{14} 450 \mathrm{mc}$ FDM printer. The accuracy in the two primary directions is $\pm 0.0015 \mathrm{~mm}$, while in the third direction the accuracy is $\pm 0.127 \mathrm{~mm}$. Hence, care should be taken to orient the mirror so that the accumulated error has the least influence on the functionality of the mirror. After an overnight production of the mirror model, aluminum foil can be carefully glued to the surface, and the prototype mirror is ready for test. We have produced and tested this type of mirrors with success quite routinely. In principle, such mirrors could be used for any ex-vessel low power microwave use. Examples of the mirrors are seen in Fig. 1.

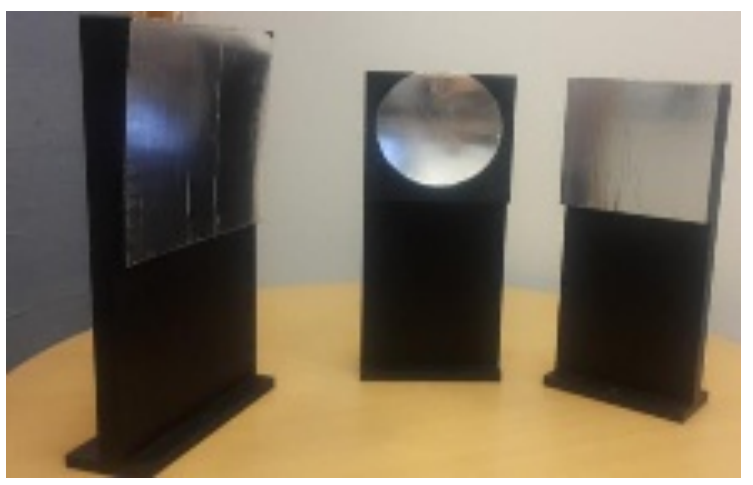

FIG. 1. Quasi-optical mirrors produced by FDM and aluminum foil.

\section{B. Horns and corrugated components}

The method described above is efficient and appropriate for smooth microwave mirror surfaces - even with significant curvature. However, more complicated structures, in particular with corrugations require a different route of production for obvious reasons.

The prototypes required to test the in-vessel transmission lines of the ITER CTS diagnostic included both miter bends and CC WGs of $\varnothing 88.9 \mathrm{~mm}$ and receiver WGs of $\varnothing 31.75 \mathrm{~mm}$. With regard to the receiver transmission lines, the primary interest was not the CC WG and miter bend transmission lines, but rather the coupling between these and the mirrors. For this reason a horn antenna was designed to serve as a microwave source for the different receiver transmission line mock-ups. The geometry of the horn antenna was chosen in a way that the beam characteristic is equivalent to a beam leaving a corrugated waveguide with a diameter of $\varnothing 31.75 \mathrm{~mm}$. Additionally, the horn was designed to be fitted to existing microwave sources in the lab, and hence the horn could not be obtained as a commercial off-the-shelf item from any vendor. As traditional manufacturing techniques would be costly and have significant lead times, we attempted other approaches that we present below - also for future benefit.

\section{3D PRINTING OF CORRUGATED MICROWAVE HORN}

\section{A. Aluminum printing}

As an alternative to machining a horn, our first attempt was to use metal additive manufacturing with aluminum to produce the horn from the CATIA file directly. We did this via an external supplier, but as the resulting horn and method is not the topic of this paper, we will not go into much detail about this. The resulting horn is shown in Fig. 2 , and it may be observed that the surface structure - even of the corrugations - is rather uneven and rough.

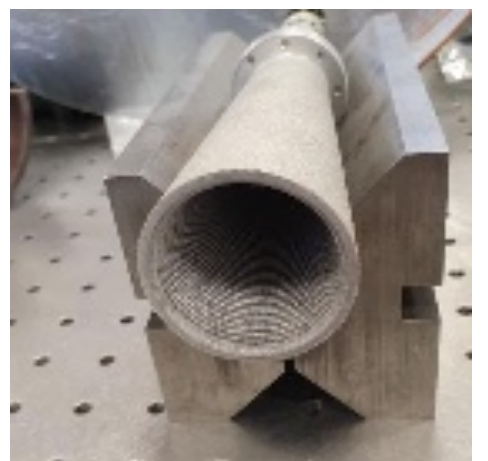

FIG. 2. Aluminum horn made by additive manufacturing.

However, as will be shown in Section V, the performance of the 3D metal printed horn is seen to be satisfactory at $60 \mathrm{GHz}$. Unfortunately, we found that the performance degraded quickly with frequency shifts of a few hundred $\mathrm{MHz}$. We did not investigate further if the reason for this was the surface structure, and neither attempted to optimize the 3D aluminum printing, as the process was relatively costly compared to the new method presented below in this paper

\section{B. Plastic printing and coating}

Following the partial success of the additive manufacturing of an aluminum horn, different routes of FDM production of the horn were attempted. The subsequent primary challenge was the addition of a 
conducting surface, though. In the final iteration, the company Polyteknik AS - experts in coating machines and coating services - took up the challenge of coating the FDM plastic horn with a conducting copper surface. The horn (shown in Fig. 3) was 3D plastic printed in two halves in order to facilitate the coating as described in the next section.

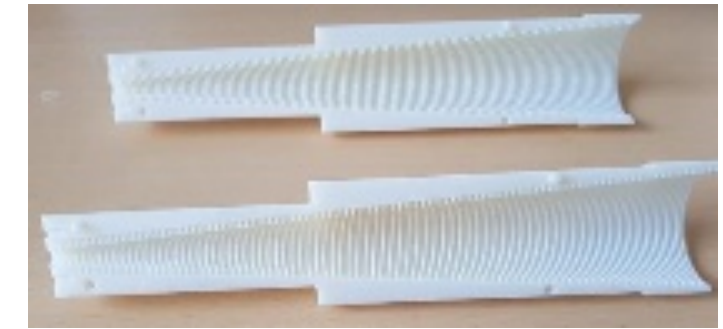

FIG. 3. $60 \mathrm{GHz}$ corrugated horn 3D plastic printed in a FORTUS ${ }^{5}$ 450mc FDM printer.

\section{COATING PROCESS}

\section{A. Experimental setup}

The thin film coating was deposited in a Polyteknik physical vapor deposition (PVD) coating system ${ }^{15}$ (See Fig. 4). The system is equipped with a single magnetron Trumpf Hüttinger Truplasma DC 3000 power supply ${ }^{16}$ and two magnetrons with a Schneider Plasmatec Bipolar power supply ${ }^{17}$. The dimensions of the magnetrons are $730 \mathrm{~mm}$ in length and $80 \mathrm{~mm}$ in width, and thus the system provides a uniformity of coating thickness (range from few nm to 20 $\mu \mathrm{m}$ ) of a few percent within the central $500 \mathrm{~mm}$. The DC magnetron was equipped with a $99.99 \%$ purity titanium target, and the two bipolar magnetrons were equipped with $99.95 \%$ purity copper targets. The magnetrons are mounted in the center of a cylindrical vacuum chamber of $650 \mathrm{~mm}$ in diameter and $850 \mathrm{~mm}$ in depth with a rotating fixture moving around on the outside.

The components to be coated are mounted on the fixture, and as they rotate around the magnetrons, they will experience deposition from a range of incident angles. Since e.g. the corrugated horn is split in two halves, the different incident angles ensure that the horn has a uniform distribution of coating along the entire half circle surface. This would not be the case if the component were passing the magnetrons in a linear motion, since part of the surface would always be perpendicular to the target surface and thus obtain a much thinner coating.

\section{B. Process Parameters}

When depositing metal coatings on polymer substrates there are many parameters that influence the quality of the deposited film and adhesion, and this section will provide a short overview of the considerations done for this project.

As a first preparation of the polymer component prior to deposition, it can be very beneficial to do some kind of plasma etching. In this project, we used a DC Glow discharge for cleaning and surface activation, before deposition of thin-film metallic coating. This removes residual contamination that could stem from handling and shipment. The plasma cleaning also activates the surface and increases the substrate temperature. This improves the chemical reactiveness for the adhesion promotion layer - in this case titanium. Titanium was chosen, since it has good adhesion to a wide range of materials. Additionally, it is also a very good barrier layer to reduce the diffusion of copper into the polymer substrate. The thickness of the titanium layer was approximately $260 \mathrm{~nm}$.

The thin film was deposited in an argon atmosphere with process pressure of $510^{-3} \mathrm{mbar}$, since this provides a sufficiently low pressure to have high impact particles hit the substrate and ensure good adhesion.

For $60 \mathrm{GHz}$ radiation the skin depth in copper is approximately $266 \mathrm{~nm}$, and to ensure a conducting layer of four to five times the skin depth, the copper layer was targeted to be more than $1 \mu \mathrm{m}$ thick - in fact it was 1232 $\mathrm{nm}$. This ensures that more than $99 \%$ of the current induced by the $60 \mathrm{GHz}$ waves will flow in the top coated layer. The coating thickness was measured on a glass witness sample using a Bruker Dektak XT profilometer ${ }^{18}$.

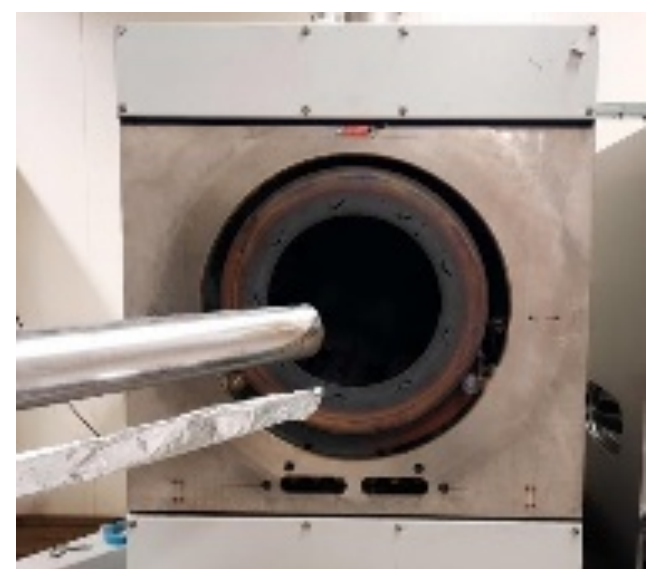

FIG. 4. Polyteknik PVD coating system equipped with a single magnetron Trumpf Hüttinger Truplasma 3000 V DC power supply and two magnetrons with a Schneider Plasmatec Bipolar power supply

The copper coated 3D plastic printed horn is shown in Fig. 5, where the exterior indeed appears as a solid copper horn. The process thermal power exerted onto the plastic horn in combination with the rather thin walls of the horn resulted in a minor loss in circularity of the horn. This was remedied in the microwave lab by fixing the horn inside a simple sleeve/tube of aluminum. The loss of circularity was only observed with this horn prototype and not in more solid components, like CC WGs and miter bends. It may be avoided in the future by ensuring thicker walls of the components or by adjusting the combination of power and exposure time of the coating process. 


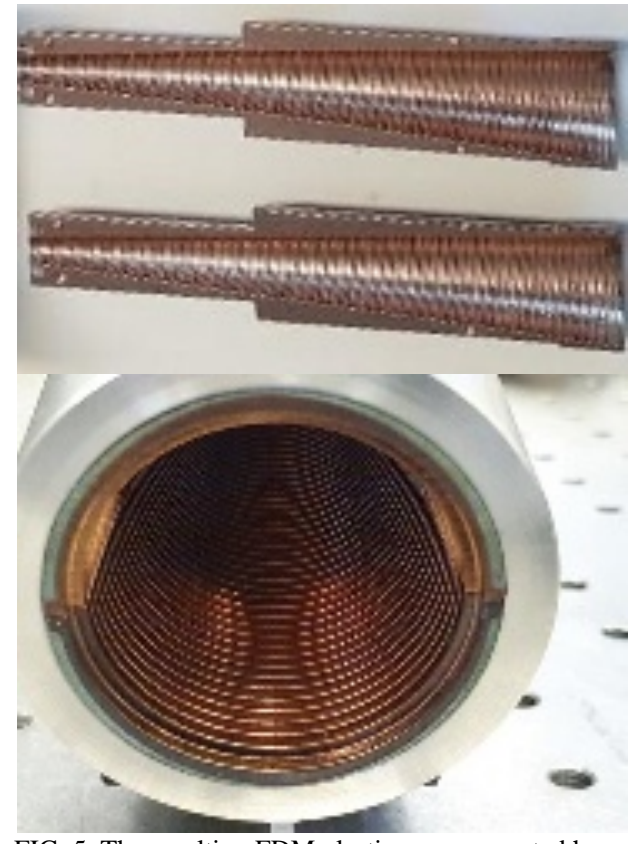

FIG. 5. The resulting FDM plastic, copper-coated horn

\section{MEASUREMENTS OF THE PERFORMANCE}

The performance of the copper-coated corrugated microwave horn was tested in the DTU Physics microwave lab. In this section, we describe the test setup followed by the results of the performance tests.

\section{A. Microwave test setup}

The microwave lab is equipped with a beam characterization setup ${ }^{3}$. The device under test - here the copper coated horn - is connected to a microwave source: a Voltage Controlled Oscillator VCOM-15/25, ELVA- $1^{19}$. The horn is directed towards a scanning rig that can move in a 2D plane orthogonal to the beam axis from the horn. The scanning area of the rig can be freely set within a range of $600 \mathrm{~mm}$ by $600 \mathrm{~mm}$. The scanning rig carries a microwave detector diode: a V-band Zero Biased Detector Diode ZBD-15, ELVA- ${ }^{19}$ with an open-ended WR-15 fundamental waveguide section as probe antenna. The ZBD is connected to an amplifier and a data acquisition card. The scanning rig and detector diode are shown in Fig. 6.

The setup directly gives the detector diode output voltage as a function of location in the $2 \mathrm{D}$ plane of the rig, which allows us to characterize the beam pattern of the device under test. The beam propagation can be characterized by multiple measurements at different distances between the horn and the rig.

\section{B. Results of the microwave test of the horn}

The measurement setup as described above has been used routinely for characterization of prototypes ${ }^{9}$. The beam

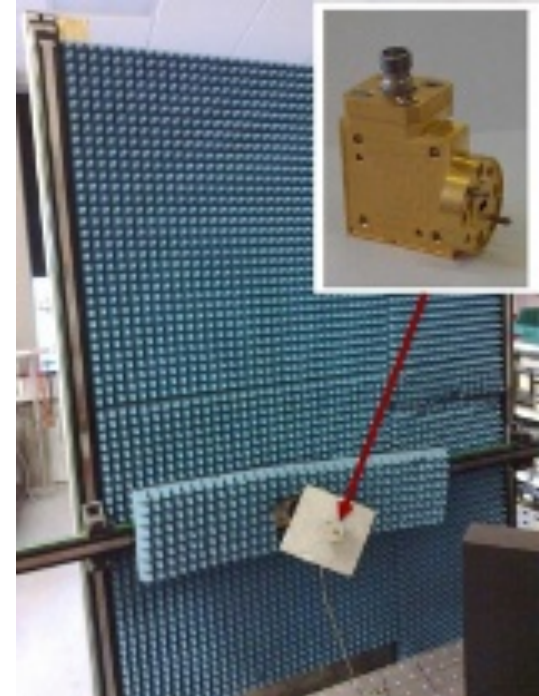

FIG. 6. The DTU microwave lab scanning detector rig. The insert shows the V-band Zero Biased Detector Diode ZBD-15.

pattern of the copper coated horn (as well as that of the aluminum 3D printed horn) was measured for several distances. An example of the horn 2D beam intensity (represented by the output voltage of the detector diode and amplifier setup) for a given distance is shown in Fig. 7.

The summary of the qualification measurements of the FDM plastic and copper coated horn - alongside the

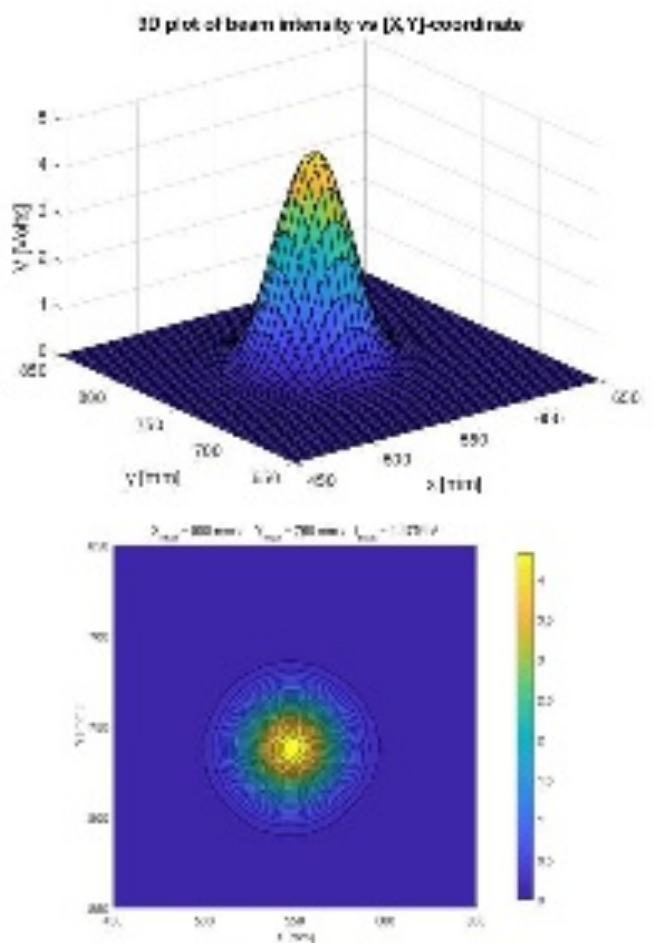

FIG. 7. Microwave beam intensity measured as detector diode output voltage as a function of position on the $(x, y)$-plane of the microwave scanning rig. (Top) 3D plot, (Bottom) 2D plot. 
measurements of the aluminum 3D printed horn - is found in Fig. 8, where the measurements are plotted with the designed and predicted Gaussian beam width (full line). Note that the measurements were made at $60 \mathrm{GHz}$. From these measurements, we can conclude that the copper coated horn performs as designed, and a series of successful prototype measurements have since been made with this horn.

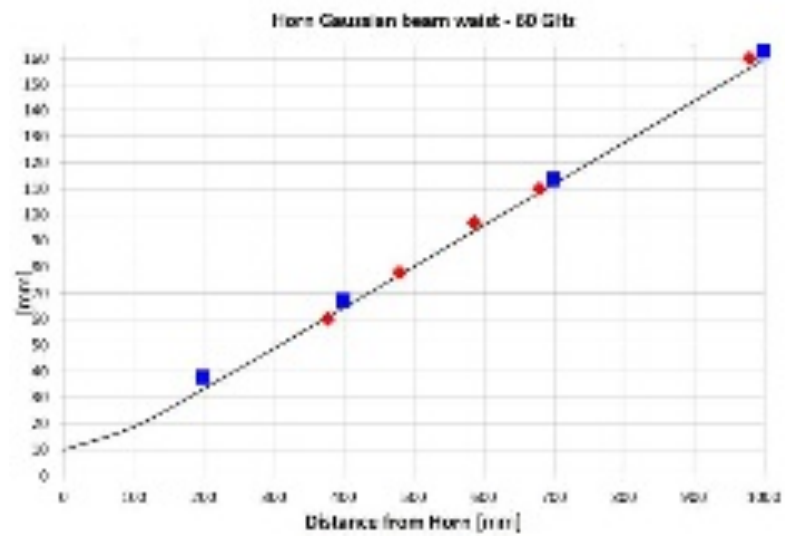

FIG. 8. Microwave Gaussian beam waist (rotationally symmetric) as a function of the distance to the horn at $60 \mathrm{GHz}$. The black line shows the expected designed waist. The red diamonds and the blue squares respectively indicate the measured + fitted Gaussian beam waists of the 3D-printed horns: aluminum (red), and FDM plastic - copper

\section{CONCLUSION AND RECOMMENDATIONS}

The article presents an efficient - both in time and resources - route towards producing corrugated microwave component prototypes by PVD copper coating of FDM plastic printed components. For low power microwaves, we demonstrate that a corrugated horn produced in this manner has a fully adequate performance similar to a pure metallic horn and within the expectations from modelling. While not demonstrated in the present paper, we have produced and tested circular corrugated waveguides and miter bends at $\varnothing 88.9 \mathrm{~mm}$ using the same processes, and the succeeding experiments confirmed the applicability of the production method for low power microwave component setups. Ultimately, not only prototypes, but also operational nonvacuum low power microwave components can be produced using the described manufacturing method.

We propose to use this production method as an alternative to the traditional manufacturing of these components by machining in copper or similar. However, it is crucial to assess the power and heat resilience of the 3D plastic used, as the PVD coating process does exert some power to the component. We found that the thin-walled corrugated horn did suffer from excessive heat and the circularity of the horn exit had to be corrected by an aluminum sleeve. This issue could be avoided in the future by either increasing the wall thickness of the horn or by performing the coating by less power over a longer processing duration. In support of this approach, we did not observe any similar issues with any of the other components we produced, since they were all more solid.

\section{ACKNOWLEDGMENTS}

The work leading to this publication has been funded partially by Fusion for Energy under the Framework Partnership Agreement F4E-FPA-393. This publication reflects the views only of the author, and Fusion for Energy cannot be held responsible for any use which may be made of the information contained therein.

\section{DATA AVAILABILITY}

The data that support the findings of this study are available from the corresponding author upon reasonable request.

\section{REFERENCES}

${ }^{1}$ S.B. Korsholm et al., "Design and development of the ITER CTS diagnostic”, EPJ Web Conf. 203, p. 03002 (2019)

${ }^{2} \mathrm{M}$. Salewski et al, "Alpha-particle velocity-space diagnostic in ITER", Nucl. Fusion 58, 096019 (2018)

${ }^{3}$ J. Rasmussen, M. Stejner, T. Jensen, E.B. Klinkby, S.B. Korsholm, A.W Larsen, F. Leipold, S.K. Nielsen, M. Salewski, "Inference of $\alpha$-particle density profiles from ITER collective Thomson scattering", Nucl. Fusion 59, 096051 (2019)

${ }^{4} \mathrm{~A}$. Lopes et al, "Neutronics analysis of the ITER Collective Thomson Scattering system”, Fus. Eng. Des. 134, pp. 22-28 (2018)

${ }^{5}$ A.W. Larsen et al, "Mitigation of EC breakdown in the gyrotron transmission line of the ITER Collective Thomson Scattering diagnostic via a Split Biased Waveguide", J. Inst. 14, C11009 (2019)

${ }^{6} \mathrm{C}$. Vidal et al, "Thermo-structural analyses of the in-vessel components of the ITER collective Thomson scattering system”, Fus. Eng Des. 140, pp. 123-132 (2019)

${ }^{7} \mathrm{~V}$. Infante et al, "RAMI analysis of the ITER LFS CTS system", Fus. Eng Des. 123, pp. 663-668 (2017)

${ }^{8}$ A. Lopes et al, "Shielding analysis of the ITER Collective Thomson Scattering system”, Fus. Eng. Des. 161, pp. 111994 (2020)

"S.B. Korsholm et al, "Current fast ion collective Thomson scattering diagnostics at TEXTOR and ASDEX Upgrade, and ITER plans (invited)", Rev. Sci. Instrum. 77, 10E514 (2006)

${ }^{10}$ S.B. Korsholm et al, "Collective Thomson scattering capabilities to diagnose fusion plasmas", Nucl. Instrum. Methods Phys. Res. 623, pp. $677-680$ (2010)

${ }^{11}$ S.K. Nielsen et al, "Recent development of collective Thomson scattering for magnetically confined fusion plasmas", Phys. Scr. 92, 024001 (2017)

${ }^{12} \mathrm{D}$. Moseev et al, "Collective Thomson scattering diagnostic at Wendelstein 7-X", Rev. Sci. Instrum. 90, 013503 (2019)

${ }^{13}$ CATIA is a CAD/CAM/CAE commercial software suite developed by Dassault Systems

${ }^{14}$ Stratasys, www.stratasys.com

${ }^{15}$ www.polyteknik.com

${ }^{16}$ www.trumpf.com/en_IN/products/powerelectronics/plasmaexcitation/truplasma-dc-series-3000/

${ }^{17}$ www.j-schneider.de/en/high-voltage-power-supplies/hv-module19/product-overview/plasmatec/plasmatec/

${ }^{18}$ www.bruker.com/products/surface-and-dimensional-analysis/stylusprofilometers/dektak-xt/overview.html

${ }^{19}$ www.elva-1.com 